\title{
SAVIJANJE DEBELIH I UMJERENO DEBELIH SLOJEVITIH KOMPOZITNIH PLOČA
}

Marina Rakočević ${ }^{1}$

УДК:539.377

Rezime: U radu je dat pregled teorijskih i numeričkih modela za proračun uticaja $u$ presjecima umjereno debelih $i$ debelih slojevitih kompozitnih ploča napregnutih na savijanje. Slojevite kompozitne ploče se dobijaju kombinacijom slojeva različitih materijalnih i geometrijskih karakteristika pri čemu svaki od slojeva nosi u jednom unaprijed definisanom pravcu. Primjenom klasičnih jednoslojnih teorija ne mogu se uspješno rješavati problemi ovih ploča zbog čega se primjenjuju savremene teorije ploča u literaturi poznate kao „Layerwise” teorije. Na kraju rada dati su numerički primjeri primjene "Partial Layerwise teorije".

Кључне речи: Slojevita kompozitna ploča, debela ploča, ,Layerwise”teorija

\section{UVOD}

Ploče su tijela kod kojih je debljina mala veličina u odnosu na ostale dvije dimenzije zbog čega se deformacija ploče može opisati preko deformacije srednje ravni ploče. Ova pretpostavka omogućava da se naponsko-deformacijska analiza ploče tretira kao 2D problem mehanike kontinuma. Pored ove pretpostavke uvode se dopunske pretpostavke za deformaciju po visini ploče. Primjenom teorija koje se zasnivaju na navedenoj pretpostavci dobijaju se rezultati čija tačnost zavisi od odnosa debljine ploče i kraće strane ploče. U zavisnosti od dopunskih pretpostavki razvijene su sljedeće opšte poznate teorije ploča: teorija tankih ploča, strožija teorija ploča i teorija ploča višeg reda.

Primjena navedenih teorija za debele i umjereno debele ploče je ograničena. Ograničenje se posebno odnosi za slučaj kada treba analizira veliki spektar problema ploča koje posjeduju anizotropne karakteristike, kao što su slojevite kompozitne ploče napravljene od slojeva koji nose u različitim pravcima, Slika 1.. Za proračun ploča anizotropnih karakteristika razvijene su savremenije teorije.

\section{TEORIJSKI MODELI SLOJEVITIH KOMPOZITNIH PLOČA}

Savremene kompozitne ploče dobijaju se kombinacijom više materijala različitih karakteristika čime se postižu bolje fizičko-mehaničke karakteristike ploče. Sloj je

\footnotetext{
${ }^{1}$ Marina Rakočević, Prof.dr., dipl.inž.građ., Univerzitet Crne gore, Građevinski fakultet Podgorica, Džordža Vašingtona bb, Podgorica, Crna Gora, tel: +382 20244 905, e - mail: marinara@ac.me
} 
International conference

Contemporary achievements in civil engineering 24. - 25. April 2014. Subotica, SERBIA

osnovni element slojevitih kompozitnih ploča i čine ga osnovna masa i neprekidna vlakna koja nose u jednom pravcu i koja su ugrađena u osnovnu masu.

Za proračun uticaja u presjecima slojevitih kompozitnih ploča na rapolaganju nam stoje sljedeće teorije, [1]:

- Ekvivalentne jednoslojne teorije

- Teorije slojeva

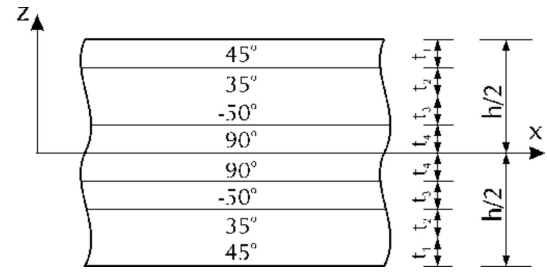

Slika 1. Slojeviti kompozit sa uglovima orijentacije slojeva

\subsection{EKVIVALENTNE JEDNOSLOJNE TEORIJE}

U ekvivalentne jednoslojne teorije, skraćeno ESL-Equivalent Single-layer LaminateTheory, spadaju: klasična teorija slojevitih ploča, smičuća teorija prvog reda i smičuće teorije većeg reda, u skladu sa teorijama koje se navedene za homogene i izotropne materijale. $\mathrm{Za}$ ove teorije karakteristično je to da se krutosti materijala računaju za ploču kao cjelinu. U jednoslojnim teorijama usvaja se jedna funkcija za promjenu komponentalnih pomjeranja po debljine ploče, pa su smičuće deformacije neprekidne po debljini. U radu su ESL teorije hijerarhijski navedene.

\section{Klasična teorija slojevitih ploča - CLPT teorija}

Klasična teorija slojevitih ploča u literaturi poznata kao CLPT - Classical Laminated Plate Theory je najjednostavnija teorija. Ova teorija zasnovana na pretpostavci da presjek nakon deformacije ostaje prav i upravan na deformisanu srednju ravan ploče, Slika 2..

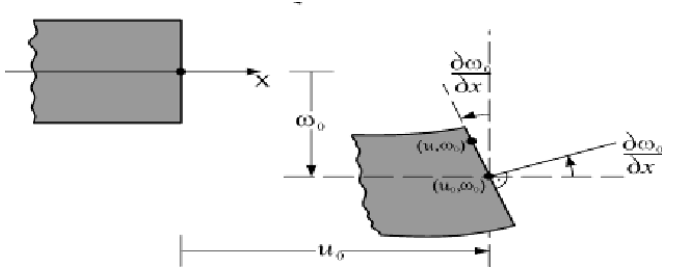

Slika 2. Deformacija presjeka - CLPT teorija

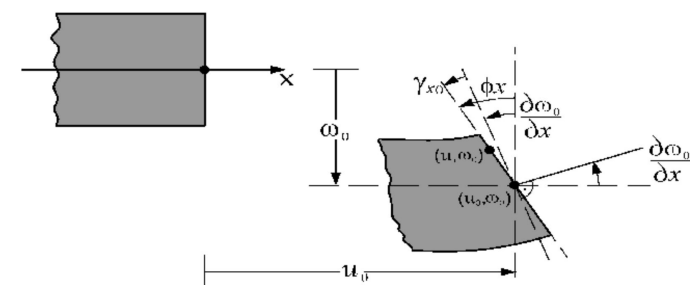

Slika 3. Deformacija presjeka - FSDT teorija

CLPT teorija se primjenjuje za tanke slojevite ploče, dok je primjena ove teorije za umjereno debele i debele slojevite ploče ograničena. 
Smičuća teorija prvog reda - FSDT teorija

Smičuća teorija prvog reda, skraćeno FSDT- First Order Shear Deformation Theory, uvodi konstantno smicanje presjeka po debljini. Prema ovoj teoriji presjek ploče koji je prije deformacije bio upravan na srednju ravan ploče ostaje prav i nepromijenjene dužine ali ne i upravan na deformisanu srednju ravan, Slika 3.. Komponentalna pomjeranja FSDT teorije data su $u$ funkciji od $\mathrm{u}_{0}, \mathrm{v}_{\mathrm{o}}, \mathrm{w}_{\mathrm{o}}$ - komponentalnih pomjeranja srednje ravni ploče i $\phi_{\mathrm{x}}$ i $\phi_{\mathrm{y}}$ - rotacije normale oko osa x i y.

I ako se primjenom ove teorije dobijaju ekonomična rješenja ona ima svoje nedostatke koji se odnose na komlikovan postupak određivanja smičićih koeficijenata za presjek sa proizvoljnim rasporedom slojeva. Primjenom MKE u rješavanju jednačina teorije, za veoma tanke ploče, javlja se problem velikog učešće deformacije klizanja u ukupnoj deformaciji ploče.

Smičuće teorije većeg reda

Kod ovih teorija smicanje po visini presjeka se opisuje funkcijama većeg stepena, Slika 4.. Razvijene su teorija smicanja drugog reda - Second-order Plate Theory i teorija smicanja trećeg reda - Third-order Plate Theory. Teorije većeg reda od teorije trećeg reda se ne tretiraju zbog neekonomičnosti.

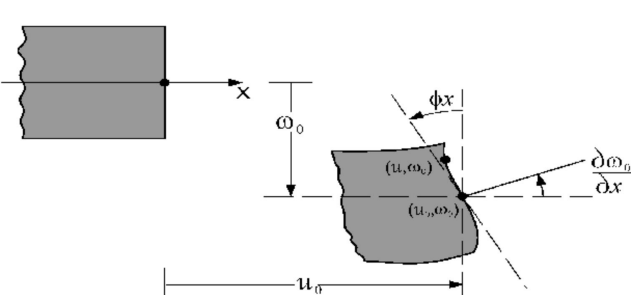

Slika 4. Deformacija presjeka-teorije većeg reda

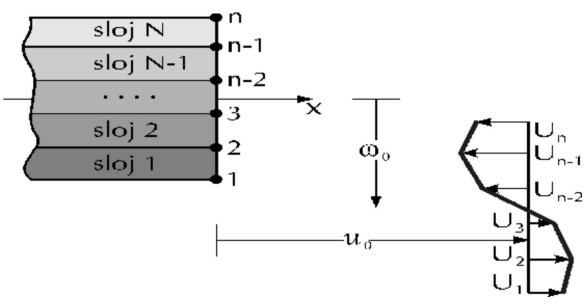

Slika 5. Layerwise teorija

Za definisanje komponentalnih pomjeranja po debljini slojevite ploče koriste se polinomi većeg reda (kvadratni ili kubni). U smičućoj teoriji trećeg reda komponentalna pomjeranja su data $\mathrm{u}$ funkciji od pomjeranja srednje ravni ploče, rotacija normala oko koridnatnih osa $\phi_{\mathrm{y}}, \phi_{\mathrm{z}}$ - rotacije normale oko osa $\mathrm{x}, \mathrm{y}$ i z i rotacija većeg reda $\psi_{\mathrm{x}}, \psi_{\mathrm{y}}, \psi_{\mathrm{z}}$, $\theta_{\mathrm{x}}$ i $\theta_{\mathrm{y}}$. Odnosno, teorije drugog i trećeg reda uključuju dodatne nepoznate koje je teško fizički interpretirati. Nedostatak teorija trećeg reda se odnosi na komlikovan postupak određivanja smičićih koeficijenata za presjek sa proizvoljnim rasporedom slojeva. Takođe, ova teorija obezbjeđuje relativno malo povećanje tačnosti uz značajno uvećanje troškova proračuna, dok se rješavanjem jednačina ove teorije primjenom Metode konačnih elemenata javlja problem kontinuiteta.

\subsection{TEORIJA SLOJEVA}

ESL teorije su jednostave, ekonomski opravdane i obezbijeđuju "dovoljnu tačnost" za tanke slojevite ploče anizotropnih karakteristika. Međutim, ove teorije ne mogu obuhvatiti većinu problema koje se mogu javiti kod slojevitih savremenih kompozitnih 
ploče. Na primjer, primjenom ovih teorija ne mogu se razmatrati materijalne i geometrijske imperfekcije na nivou sloja, uključujući i delaminacije između slojeva. Nedostatak je i to što se povećanjem debljine ploče smanjuje tačnost rješenja. Teorije slojeva omogućavaju uvođenje mnogo tačnijih modela kojim se mogu opisati naznačeni problemi. Primjenom ovih teorija kinematički mnogo tačnije se prikazuje deformacija poprečnog presjeka duž svakog sloja za umjereno debele i debele slojevite ploče. U teoriji slojeva razmatranja se sa nivoa ploče svode na nivo sloja. Svaki sloj se posmatra odvojeno, a onda se, u zavisnosti od zahtjevane tačnosti, definišu uslovi kompatibilnosti na vezama slojeva i uticaj jednog sloja na drugi uz zadovoljenje uslova ravnoteže i graničnih uslova.

Istorijski gledano, sedamdestih godina prošlog vijeka razvijene su teorije sloj po sloj (obezbijeđuju $\mathrm{C}^{0}$ kontinuitet), a nakon toga 90 -tih godina prošlog vijeka razvijena je opšta teorija slojeva (GLPT- Generalized Layerwise Plate Theory). Opšta teorija slojeva koristi postupak sloj po sloj pri čemu se u proračun uvodi i komponentalno pomjeranje u pravcu z ose i smičuće deformacije u ravnima upravnim na ravan ploče.

Opšta teorija slojeva bazirana je na ideji Reddy-ja (1987) na osnovu koje se pomjeranja mogu predstaviti kao linearna kombinacija koordinata u ravni i funkcije koordinate po debljini ploče (GLPT- Generalized Layerwise Plate Theory). Funkcija promjene komponentalnih pomjeranja po debljini ploče definiše se Langranžovim interpolacionim funkcijama zbog čega su pomjeranja neprekidna i omogućavaju da naponi po debljini mogu biti prekidni na vezama slojeva različitih materijalnih karakteristika.

U teoriji slojeva vrši se diskretizacija po debljini ploče pri čemu broj elemenata može biti veći, jednak ili manji od broja slojeva. Uobičajeno je da se svaki sloj tretira kao jedan element, Slika 5.. U zavisnosti od usvojenog polja pomjeranja, odnosno polja osnovnih nepoznatih, u teoriji slojeva definišu se sljedeće teorije:Potpuna teorija slojeva - Full Layerwise theory i Parcijalna ili Nepotpuna teorija slojeva - Partial Layerwise Theory). U slučaju kada se pretpostavi da je komponentalno pomjeranje u pravcu $\mathrm{z}$, $\mathrm{w}=\mathrm{w}(\mathrm{x}, \mathrm{y})$, konstantno po debljini ploče i kada se pretpostavi da je odgovarajuća normalna deformacija $\varepsilon_{\mathrm{z}}=0$, dobija se specijalan slučaj teorije slojeva. Teorija zasnovana na ovim pretpostavkama je Nepotpuna teorija slojeva, a komponentalna pomjeranja ove teorije definisana su sa:

$$
\begin{aligned}
& u(x, y, z)=u(x, y)+U(x, y, z) \\
& v(x, y, z)=v(x, y)+V(x, y, z) \\
& w(x, y, z)=w(x, y)
\end{aligned}
$$

gdje su: $u(x, y), v(x, y), w(x, y)$ pomjeranja srednje ravni ploče, a $U(x, y, z)$ i $V(x, y, z)$ dodatna pomjeranja po debljini ploče.

\section{SAVIJANJE SLOJEVITIH KOMPOZITNIH PLOČA}

U Nepotpunoj teoriji slojeva uslovne jednačine za probleme savijanjana ploča dobijaju se primjenom principa virtualnih pomjeranja, a za slučaj kada ne postoji promjena kinetičke i toplotne energije ploče. Uslovne jednačine problema savijanja slojevitih ploča čini sistem od 3+2N jednačina, gdje je $\mathrm{N}$ broj slojeva, [2],[3]:

\section{2 | JOURNAL OF FACULTY OF CIVIL ENGINEERING (2014)|}




$$
\begin{gathered}
N_{x, x}+N_{x y, y}=0 \\
\mathrm{~N}_{\mathrm{xy}, \mathrm{x}}+\mathrm{N}_{\mathrm{y}, \mathrm{y}}=0 \\
\mathrm{Q}_{\mathrm{x}, \mathrm{x}}+\mathrm{Q}_{\mathrm{y}, \mathrm{y}}+\mathrm{q}=0 \\
\mathrm{~N}_{\mathrm{x}, \mathrm{x}}^{\mathrm{j}}+\mathrm{N}_{\mathrm{xy}, \mathrm{y}}^{\mathrm{j}}-\mathrm{Q}_{\mathrm{x}}^{\mathrm{j}}=0 \\
\mathrm{~N}_{\mathrm{xy}, \mathrm{x}}^{\mathrm{j}}+\mathrm{N}_{\mathrm{y}, \mathrm{y}}^{\mathrm{j}}-\mathrm{Q}_{\mathrm{y}}^{\mathrm{j}}=0
\end{gathered}
$$

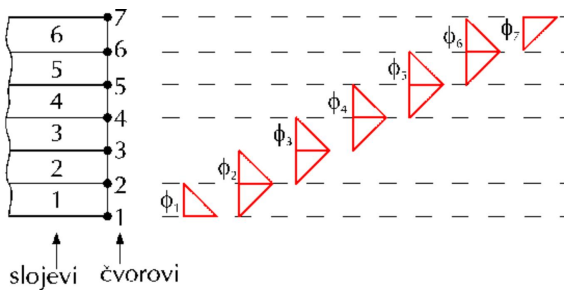

Slika 6. Linearne interpolacione funkcije

Za svaki sloj koji se tretira kao 1D element po debljini ploče usvajaju se linearne interpolacione funkcije. Na Slici 6. prikazane su usvojene interpolacione funkcije za slučaj kada je broj slojeva $\mathrm{N}=6$ i broj čvorova $\mathrm{n}=7$.

Rješenja uslovnih jednačina problema (2) mogu se dobiti u zatvorenom obliku ili numerički.
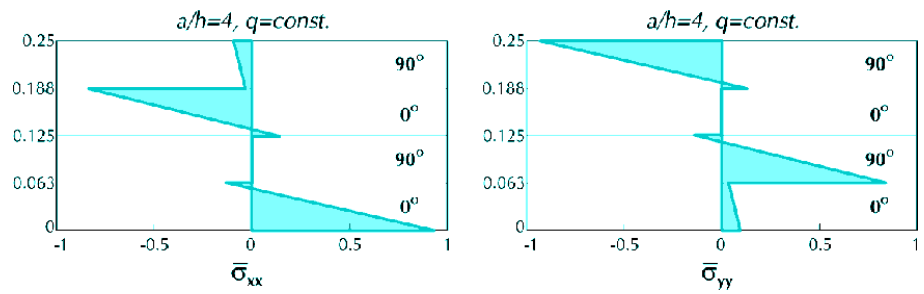

Slika 7. Raspored normalnih napona po debljini slojevite ploče $0^{\circ} / 90^{\circ} / 0^{\circ} / 90^{\circ}$
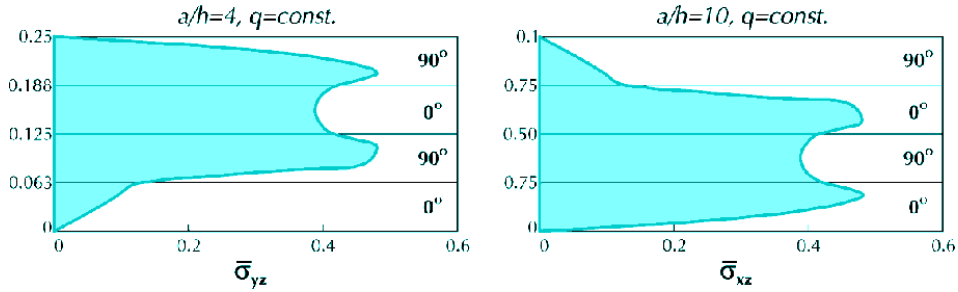

Slika 8. Raspored smičućih napona po debljini slojevite ploče $0^{\circ} / 90^{\circ} / 0^{\circ} / 90^{\circ}$

Analitičko rješenje se dobija primjenom dvostrukih redova uz zadovoljenje graničnih uslova na konturi ploče,[2]. Za četvoroslojnu ploču $0^{\circ} / 90^{\circ} / 0^{\circ} / 90^{\circ}$ koja je slobodno 
International conference

Contemporary achievements in civil engineering 24. - 25. April 2014. Subotica, SERBIA

oslonjena duž sve četivi konture na Slikama 7. i 8. dati su normalni i smičući naponi u bezdimenzionom obliku za slučaj dejstva ravnomjerno raspodijeljenog opterećenja.
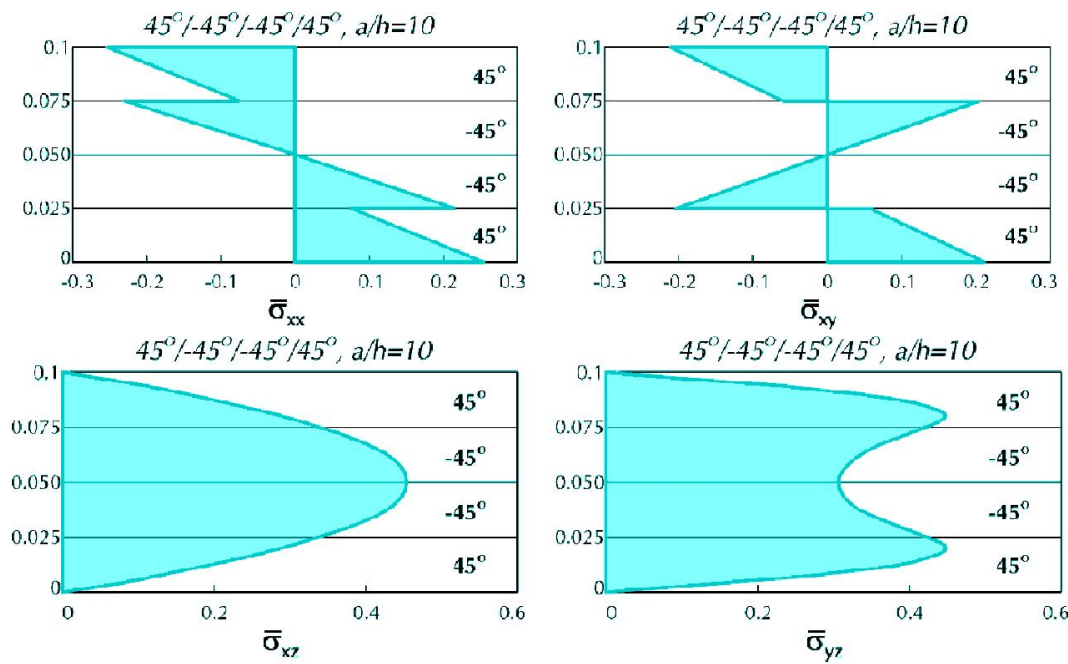

Slika 9. Raspored napona po debljini slojevite ploče $45^{\circ} /-45^{\circ} /-45^{\circ} / 45^{\circ}$

Sistem jednačina (2) numerički se rješava primjenom Metode konačnih elemenata [3] pri čemu se uvode dva tipa interpolacionih funkcija. Prvi tip su interpolacione funkcije u ravni, a drugi tip su interpolacione funkcije po debljini ploče koje su funkcije jedne promjenljive z. Interpolacione funkcije u ravni mogu biti funkcije odabrane iz širokog spektra standardnih interpolacionih funkcija za $2 \mathrm{D}$ problem. Interpolacione funkcije po debljini ploče mogu biti linijske, kvadratne ili funkcije većeg reda. $\mathrm{Na}$ Slici 9. dati su naponi $\mathrm{u}$ bezdimenzionom obliku dobijeni primjenom MKE za slobodno oslonjenu pravougaonu četvoroslojnu ploču simetričnog rasporeda slojeva $45^{\circ} /-45^{\circ} /-45^{\circ} / 45^{\circ}$ i usvojeni E4-L4 konačni element.

\section{ZAKLJUČAK}

Za rješavanje problema savijanja debelih i umjereno debelih slojevitih ploča koje su dobijene kombinacijom slojeva koji nose u različitim pravcima i koji su napravljeni od savremenih kompozitnih materijala, preporučuju se "layerwise" teorija koja razmatraju problem na nivou sloja. Ove teorije su jednostavnije od 3D teorija, a zasnovane su na ideji dobijanja rješenja kombinacijom 2D i 1D problema. Diskretizacijom po debljini ploče omogućava se da problemi geometrijskih nesavršenosti budu opisani jednostavnim dodavanjem odgovarajućih članova u pretpostavljenom polju pomjeranja. 


\section{LITERATURA}

[1] Rakočević,M.:Teorijski modeli slojevitih kompozitnih ploča, Treći inrernacionalno naučno-stručni skup Građevinarstvo-nauka i praksa, Zbornik radova Knjiga 1, 1519februar Žabljak, 2010,str.141-146.

[2] Rakočević,M.,Vuksanović,Đ.: Analitičko rješenje slojevitih pravougaonih kompozitnih ploča, Monografija 20 godina Građevinskog fakulteta $u$ Podgorici,2000,str.253-266.

[3] Rakočević,M.:Proračun sastavljenih slojevitih ploča, izvorni znanstveni rad, Građevinar, 2011, vol.63,str.819-825.

\section{BENDING OF THICK AND MODERATE THICK LAMINATED COMPOSITE PLATES}

Summary: Review of theoretical and numerical models for defining the stress-strain state in the cross section of moderately thick and thick laminated composite plates in case of bending is presented in this paper. Layered composite plates are constructed by combining layers with different material and geometrical characteristics of each layer. These layers have bearing capacity in previously defined directions. The problem of laminated composite plates cannot be successfully solved by applying the Equivalent Single-layer Laminate Theory or ESL theory. Contemporary theories of plates, in the literature known as Layerwise Plate Theory, are more applicable for these plates. At the end of this paper numerical examples for the Partial Layerwise Theory are given.

Keywords: laminated composete plates, thich plate, Layerwise theory 